\title{
LA IGLESIA Y LA FALANGE \\ THE CHURCH AND THE PHALANX
}

CaYetano NúÑEz Rivero

UNED

JuAn JACOBo NúÑEZ MaRTíNeZ

Universidad Rey Juan Carlos

Resumen: Durante la guerra civil española, las relaciones entre la Iglesia y la Falange no estuvieron exentas de conflictos, como consecuencia de la influencia nacional-socialista en el partido fascista español, así como los intentos del partido único por controlar parcelas del poder de la Iglesia.

Absract: During the Spanish civil war, the relations between the Church and the Phalanx were not exempt from conflicts, as consequence of the influence National Socialist in the fascist Spanish party, as well as the attempts of the only party for controlling plots of the power of the Church.

Palabras claves: Iglesia, Falange,Vaticano, Alemania, Nacional socialismo, Encíclica.

Keywords: Church, Phalanx, Vatican, Germany, National socialism, Encyclical.

Sumario: 1. Sobre la influencia alemana en la Falange. 2. La colaboración entre la Falange y la jerarquía católica española. 3. Sobre el clero falangista.

Recepción original: 02/10/2016.

Aceptación original: 02/10/2016.

(C) UNED. Revista de Derecho UNED, núm. 19, 2016 
Summary: 1. On the German influence German in the Falange. 2. La collaboration between the Falange and the catholic Spanish hierarchy. 3. On the Falangist clergy.

\section{SOBRE LA INFLUENCIA ALEMANA EN LA FALANGE.}

Durante el periodo de la Guerra civil, la Jerarquía Eclesiástica y el Vaticano ${ }^{1}$ mostraron ciertos recelos del concepto totalitario de los fascismos, especialmente del nacional-socialismo y de la influencia que el mismo pudiera tener en la Falange, «en cuanto en éstos, en su espiritu predomina el sentimiento de patria sobre el de religión; y el sentido de fuerza disciplinada prevalece sobre el sentimiento cristiano. Además, la suerte adversa de las armas de los marxistas ha hecho que muchos, aventureros o ventajistas o indiferentes, se hayan alistado en las filas de la Falange lo que puede constituir un peligro para esta organización. Ello importa la necesidad, sentida por todos y manifestada por varios Obispos y sacerdotes celosos, de un intenso apostolado que evite la desviación de Falange en un sentido aconfesional u hostil a la Religión ${ }^{2}$. Para ello sería de gran eficacia, mientras dura la campaña, que se organizara debidamente el cuerpo de sacerdotes que hoy desempeña ministerios en los frentes de combate» ${ }^{3}$.

Existen varios testimonios de la inquietud de la jerarquía católica española sobre la influencia nazi en la falange ${ }^{4}$, valga como ejemplo al

1 Sobre la crítica del Vaticano al nacional socialismo, véase la Encíclica Mit Brennender Sorge del 14 de marzo de 1937, leída en las Iglesias alemanas el 23 del mismo mes, en la que El Papa Pío XI, hace una durísima crítica al régimen político hitleriano y a los principios sustentadores del mismo.

2 Ello no obsta, para que la prensa falangista, especialmente la de carácter local, abundara en proclamaciones apologéticas, de carácter integrista de defensa de la «religión nacional», valga al respecto el ejemplo de «El Amanecer» de Zaragoza, que el 3 de junio de 1937, manifestaba, "Destruiremos en nombre de Dios, todo insulto a nuestra fe que venga con las apariencias de un catolicismo moderado y europeo. Nuestra fe imperial y española es limpia, ardiente y misionera... No queremos para nuestro catolicismo frigidez, tolerancia, política social, metodismo y bajas intenciones. Queremos santidad, ardiente, grande y alegre santidad. Y nuestra vieja fe, intransigente y fanática».

${ }^{3}$ Informe del Cardenal Gomá a Secretaría de Estado. Tercer informe sobre la situación de España con motivo del levantamiento cívico-militar. 24 de octubre de 1936. Documento 1-333. Sección 1. ${ }^{a}$ Legajo A. Carpeta I. Archivo Gomá. En las citas correspondientes al Archivo Gomá, se ha decidido incluir el número de documento que figura en la extraordinaria recopilación que del mismo hacen José Andrés Gallego y Antón Pazos.

${ }^{4}$ En todo caso, la Jerarquía Eclesiástica española, salvo en contadísimos casos no quiso culpar directamente a la Falange de las críticas a la Iglesia, achacándolo a la influencia extranjerizante (Alemania), tal es el caso del acto del 24 de enero de 1938 
respecto, la carta que el Primado de España remite al Cardenal Ilundain, Arzobispo de Sevilla, el 30 de junio de 19375, «(...)Ahora, que el problema de Falange se presenta delicadísimo, y más porque tengo recogidos varios datos que revelan que Falange, ni anda por sí sola, ni por los caminos trillados de nuestra tradición y del sentido verdaderamente español, tan profundamente cristiano. Creo que se nos avecinan días de lucha, por razones que tengo indicadas a la Santa Sede en mis últimas informaciones. En retaguardia, y abusando de la situación de privilegio que les ha creado el auxilio que prestan a España, se están moviendo ciertos señores cuya ideología es totalmente distinta de la nuestra y que procuran inculcar en Falange, que en algunos sitios y en algunas cosas es demasiado dócil instrumento.

Creo que debemos estar alerta, vigilando al lobo que merodea alrededor de nuestro aprisco. Si el mal crece y lo juzgare necesario vería de indicar la conveniencia de una reunión de Metropolitanos, de los que pudiésemos, a fin de prevenir hechos desagradables... ${ }^{6}$.

A tal efecto, el propio Primado, tras advertir en carta de 4 de abril de 1937 al secretario de Estado del Vaticano sobre la influencia nazi en el Gobierno Nacional, "El temor de que las cosas de la política en España tomen, si no un rumbo que podríamos llamar hitleriano, que no encajaría con la conciencia católica de nuestro país, a lo menos una orientación disconforme con nuestra tradición y con el respeto profundo que a la Santa Sede ha profesado siempre nuestra nación» ${ }^{7}$, expone

en que se clausuraba el II Congreso de las Secciones Femeninas de FET y de las JONS y donde algunos oradores hicieron una dura crítica al Sumo Pontífice "frases de pésimo gusto con respecto al Santo Padre» (las define Gomá en carta al Cardenal Pacelli). Documento 9-138. Legajo A. Carpeta IV. Documento 1.

${ }^{5}$ La carta responde a otra remitida por el Arzobispo de Sevilla, en la que solicita el consejo de Gomá sobre su posible participación en un número extraordinario del 18 de julio de la prensa falangista local. Documento 6-184. Sección 1 . $^{\mathrm{a}}$ Legajo D. Carpeta V:A. Documento 15. Archivo Gomá.

6 Documento 6-204. Sección 1. a Legajo D. Carpeta V:A. Documento 16. Archivo Gomá.

7 En la decidida defensa que la jerarquía católica española hace del «movimiento nacional», destacan sobre todo dos aspectos la defensa del catolicismo y el anticomunismo, a los que debe unirse el concepto de conservación de las tradiciones y valores del confesionalismo estatal, así lo manifiesta el Primado en varias ocasiones, valga como ejemplo la carta del mismo al Secretario de Estado vaticano, de 30 de abril de 1937, «Comparto hasta cierto punto los temores que la Santa Sede abriga sobre la posibilidad de que en lo futuro las relaciones jurídicas de la Iglesia con el Estado no logren en España aquel grado de concordia que sería de esperar de nuestra tradición católica, de la forma como las han llevado en tiempo menos azarosos los gobiernos de la monarquía y hasta de la que sería de esperar de la reviviscencia del espíritu cristiano en nuestro país y de la misma naturaleza del movimiento nacional... movimiento que tiene como resorte más fuerte y profundo el espíritu religioso de los combatientes...». Sección 1. ${ }^{\circ}$ Legajo A.Carpeta II. Documento 60. Archivo Gomá. De esta forma, es muy raro

(C) UNED. Revista de Derecho UNED, núm. 19, 2016 
su deseo de redactar un pequeño tratado sobre materias de derecho público eclesiástico "especialmente relacionadas con la situación actual de nuestras cosas en España» ${ }^{8}$.

Son numerosos los testimonios, tanto del Vaticano como de la propia jerarquía eclesiástica española, referentes al temor de que se produjera una cierta hitlerización en el Gobierno Nacional, en virtud de la influencia que la Falange pudiera tener en la organización del Nuevo Estado 9 . Es por ello, que apoyarán el decreto de unificación, por el que se integraban los diversos movimientos y partidos en el bando nacional, de tal forma, que esperaban que el peso de los requetés contrarrestara la influencia falangista, lo que no obsta, para que mantenga algunas reservas al respecto, como consecuencia de la preponderancia falangista y las divergencias entre los componentes de la misma ${ }^{10}$.

Especialmente destacable al respecto es el denominado caso Hedilla, Jefe de la Falange española y representante del ala más pro alemana del fascismo español; en este caso, con motivo de unas declaraciones del citado líder falangista, en las que abogaba por una cierta separación de la Iglesia y el Estado, en la prensa italiana, y ante la preocupación causada al respecto en el Vaticano, que a este respecto remite por medio del Secretario de Estado, carta al Primado de España ${ }^{11}$ con el fin de que haga gestiones ante el General Franco para descalificar dichas declaraciones, lo que cumplirá Isidro Gomá cursando

encontrar en la documentación eclesiástica referencias a aspectos de política social, aspecto que en este caso protagonizaba la falange española.

8 Doc. 123. Sección 1. ${ }^{\mathrm{a}}$ Legajo A. Carpeta II. Documento 49. Archivo Gomá.

9 Entre estos testimonios cabe destacar el del Arzobispo de Tarragona, Vidal i Barraquer, ausente de España y que se negó a firmar la Carta Colectiva de los Obispos españoles, que llega a equiparar el nazismo con el comunismo, «(...) Lo urgente es procurar que la futura paz a base de Franco, sea verdaderamente cristiana cimentada en las últimas encíclicas del Papa Pío XI, excluyendo todo comunismo ateo con sus fautores y aliados y todo nazismo y racismo, ambos perseguidores y enemigos de nuestra santa Religión». Documento 6-152. Sección 1. ' Legajo Carpeta IV. Documento 19. Archivo Gomá.

${ }_{10}$ «El Decreto y la fusión consiguientes fueron prematuros. Ni Falanges ni Requetés estaban preparados para ello. A pesar d que el Secretariado encargado de la dirección de la fusión y los organismos inferiores han realizado un laudable esfuerzo, no han conseguido más, ante la pugna por prevalecer una agrupación sobre otra, que ahondar las diferencias que las separan. En el mismo seno del Secretariado -lo sé por sus mismos componentes- se ha originado un estado de tensión que inutiliza sus esfuerzos. No podía ser de otra forma, por la distancia enorme que separa la ideología, la historia y las tendencias de las dos fracciones.» Sección 1. ${ }^{a}$ Legajo A. Carpeta III. Documento 48. Archivo Gomá.

${ }^{11}$ Documento 5-28. Sección 1. ${ }^{a}$ Legajo A. Carpeta II. Documento 59. Archivo Gomá. 
las respectivas órdenes al respecto a Despujol ${ }^{12}$ y a Gregorio Mondrego, Obispo Auxiliar de Toledo, que se encontraba en Salamanca ${ }^{13}$. En el informe remitido por el Primado a la Secretaría de Estado resultado de sus gestiones ${ }^{14}$, se manifiesta, reproduciendo la opinión del General Franco, "Comentando el General las palabras de Hedilla sobre el lema de la Falange: Patria, pan y justicia, las reprueba con energía y desagrado, como expresión demasiado materialista de las actividades $u$ orientaciones de España. Las contrapone al lema tradicionalista de Dios, Patria...Deja el General entrever en su conversación que le agrada el espíritu del Requeté tradicionalista, al que llama-solera de España-; y que éste será siempre un contrapeso para rectificar las orientaciones de Falange en lo que pudiese tener de desviación o tibieza o debilidad en la confesión de ideales religiosos de la España tradicional». En el citado informe, el Cardenal Gomá apoyándose en otras fuentes, tiene manifestaciones de especial dureza para el citado líder falangista «Es evidente que el Generalísimo no puede confiarse a un hombre menos que mediocre y con audacia, el cual, además de no saber nada de nada, puesto que ni estos tres discursos que ha pronunciado hasta ahora son de su pluma, sino escritos por secretarios a sueldo,..no posee dotes de mando. Porque aun siendo un analfabeto...iqué sería de un Gobierno con la hegemonía del grupo hedillista? No quiero ni pensarlo, máxime cuando en el orden religioso no posee la menor idea de lo que sea o deba ser el, digamos Estatuto de la Iglesia de Roma con la nueva España». Finaliza el documento con la plena descalificación del líder falangista, sobre cuyas declaraciones más o menos hitlerianas, afirma, no son dignas de tomarse en cuenta, «en todo caso tiene el valor de un sintoma sobre el que hay que estar alerta, o de una tendencia de un grupo simpatizante con las novísimas orientaciones del Estado totalitario y -sobrehumano-».

Catorce días después de este escrito, el General Franco firmaba El Decreto de Unificación y poco después Hedilla, junto con otros camaradas de la Falange era condenado a muerte. No puede medirse la influencia de la jerarquía eclesiástica en el derrocamiento del líder fascista, aunque sí queda claro de los documentos anteriormente expuestos, que la misma hizo numerosas gestiones ante la órbita del poder próximo a Franco para minimizar la actuación del segundo jefe nacional de la Falange.

${ }^{12}$ Carta del 12 de abril de 1937. Documento 5-80. Sección 2. ${ }^{a}$ Legajo G. Sin clasificar. Archivo Gomá. Gomá.

${ }^{13}$ Documento 5-129. Sección 1. ${ }^{\text {a }}$ Legajo A. Carpeta II. Documento 60. Archivo

${ }^{14}$ Ibídem. 
En todo caso, son numerosos los documentos de apoyo al proceso de unificación de las fuerzas políticas llevado a cabo por el general Franco, por parte de la Iglesia, de tal forma, que el Primado de España, en escrito remitido a Pacelli, no duda en calificarlo como «un acto de verdadero estadista, realizado con gran prudencia y que, a más de salvar a España de un gravísimo peligro, podrá ser fecundo en bienes de todo orden ${ }^{15}$.

\section{LA COLABORACIÓN ENTRE LA FALANGE Y LA JERARQUÍA CATÓLICA ESPAÑOLA}

Desaparecido el sector más radical de la Falange, las relaciones entre el partido único FET y de las JONS y la Iglesia católica pasarán a ser de estrecha colaboración, hasta el punto de que el partido único solicite al episcopado español le proporcione nombres de personas de su confianza para la provisión de cargos de responsabilidad en el nuevo régimen, como pone de manifiesto el escrito de 17 de junio de 1937, remitido por Ladislao López Bassa, miembro del Secretariado Político de FET y de las JONS a los diferentes Obipos españoles, así como al Primado de España, "Excmo. y Rdmo. Sr: Siendo misión, quizá la más importante, de este Secretariado, poder proporcionar en su día a S. E. el Generalísimo y CAUDILLO del Movimiento una relación de hombres con sentido de responsabilidad, absoluta competencia, solvencia moral y adhesión a la causa Nacional, me permito suplicar de la bondad y patriotismo de V. E. remita a esta Secretaría nombres de diez a quince personas de esa provincia, de edad comprendida entre 30 y 45 años, sin excesiva historia política anterior al Movimiento y que, hallándose en la actualidad afiliadas a FET y de las JONS ofrezcan a V.E. plena garantía.

Al mismo tiempo le suplico remita sucinta relación de aquellas personas que, gozando de gran prestigio, estuvieron siempre apartadas de toda actuación política y de aquellas otras que actuaron en partidos de derecha y actualmente no pertenecen a FET y de las JONS (...) » ${ }^{16}$.

Este requerimiento, aunque fue debidamente cumplido por una parte de la jerarquía eclesiástica española, valga como ejemplo de ello, la carta remitida por el Arzobispo de Zaragoza al Arzobispo de Toledo, "Mi venerado y querido Sr. Cardenal: Recibi la consabida circular del Secretariado Político de Falange Española Tradicionalista y de las JONS. Ya contesté enviando nombres de personas de catolicismo acen-

15 Documento 5-299. Sección 1. ${ }^{a}$ Legajo: A. Carpeta III. Documento 10. Archivo Gomá.

${ }^{16}$ Sección 1. ${ }^{\text {a }}$ Legajo D. Carpeta IV. 5. Documento 1. Archivo Gomá. 
drado, recomendables por todos los conceptos» ${ }^{17}$, sin embargo, originó una protesta de algunos Obispos ${ }^{18}$ y del Primado de España ante Juan Antonio Sangróniz, Jefe del Gabinete Diplomático de Franco, en cuanto el mismo, como otros implicaban una cierta subordinación de la jerarquía eclesiástica española ante los deseos de la autoridad civil, "Me ha sorprendido esta circular porque nunca en los anteriores regímenes un subalterno se dirigía a las supremas autoridades es objeto de la circular, mucho le agradecería evitara en lo sucesivo que esto ocurra.... Pueden contar en absoluto con la cooperación del Episcopado para todo lo que sea útil y necesario en bien de la Patria. Su mayor deseo es el de servir a España, pero también es preciso que se observen aquellas normas que se ajustan a las exigencias de institución tan elevada.» ${ }^{19}$ Queja que contrasta vivamente con el escrito que un día después de ésta, el 27 de junio, envía al funcionario López Bassa, que remitiera el ofrecimiento de colaboración, en la que le manifiesta, "Mi distinguido Señor: A mi regreso de Toledo hallo su grata carta circular de fecha 17 del corriente. Enterado de cuanto en la misma me expone tenga la seguridad de que tomo con todo interés su petición. Pero debo hacerle observar lo difícil que es para mi poder dar nombres: estoy ausente, debido a las circunstancias de la diócesis, la que está en sus tres cuartas partes dominada por los rojos: en la que han sido asesinados todos los elementos de valor y prestigio, comenzando por la capital en la que las víctimas fueron setecientas. En esta situación no es fácil corresponder a sus deseos y petición; sin embargo, los tendré muy presentes. Atentamente le saluda y de corazón le bendice s.s.» ${ }^{20}$.Con esta reacción del Cardenal Gomá, que puede calificarse a todas luces, de al menos contradictoria, posiblemente quería marcar las diferencias entre la máxima representación eclesiástica española, en cuanto el Primado gozaba de la representación vaticana ante el Gobierno Nacional y el resto de la misma, situando a la primera como la única de interlocución válida con los poderes de Estado y exenta de censura gubernamental a diferencia del resto del clero; así parece al menos, desprenderse de la circular que el Cardenal remite al episcopado español el 30 de junio de 1937, "Por todo ello,, y porque he recibido de varios Hermanos con-

17 Sección 1. ${ }^{a}$ Legajo D. Carpeta IV.4. Documento 6. Archivo Gomá.

18 Véanse al respecto las cartas dirigidas al Primado por los Obispos de Tarazona, Orense, Granada, Teruel, Palma, Málaga, Vich y Palencia, en el caso de este último se percibe igualmente la protesta por la utilización de los párrocos en las Comisiones o Juntas locales por parte del Gobierno. Documento 6-251. Sección 1. ${ }^{a}$ Legajo D. Carpeta IV.4. Documento S/C. Archivo Gomá.

${ }_{19}$ Documento 6-169. Sección 1. ${ }^{\mathrm{a}}$ Legajo D. Carpeta IV.4. Documento 3. Archivo Gomá.

${ }^{20}$ Documento 6-177. Sección 1. a Legajo D. Carpeta IV. Documento 2. Archivo Gomá.

(C) UNED. Revista de Derecho UNED, núm. 19, 2016 
sultas y quejas sobre este asunto, me he permitido escribir a la Autoridad competente para que en lo sucesivo se eviten estas consultas o requerimientos hechos por personajes subalternos, dándole al mismo tiempo la seguridad de que nos hallará siempre dispuestos a secundar cuando sea conducente al bien de la patria, dirigiéndose en forma más autorizada, para los asuntos de carácter general, al representante oficioso de la Santa Sede, mientras Esta no disponga otra forma de representación, o si ello no se juzgare oportuno, directamente a los Sres. Obispos, a quienes en este caso debería concederse exención de la censura» ${ }^{21}$. Por otra parte, el Primado de España, como se indica en la circular de referencia no desea publicidad al respecto ni una mayor involucración política al respecto, «(...) creo que se impone la prudencia máxima, y hasta tal vez una inhibición discreta, o dando simplemente nombres de personas de solvencia bajo el punto de vista católico, que es el que incumbe a nuestro ministerio». En sentido similar se dirigirá el Cardenal Gomá a José Antonio Sangróniz solicitando no se otorguen cargos políticos a los párrocos, en virtud de la difícil situación que crean a los mismos, "..ha habido casos en que por el cargo que ejerce el Cura ha debido imponer multas, denunciar feligreses etc..creo es interés de todos que los sacerdotes no actúen públicamente, ni de lejos ni de cerca en la cosa política ni en las inevitables luchas entre partidarios de uno u otro bando. Pierden su prestigio y su obra sacerdotal es ineficaz... Por desgracia no desconoce $V$ con qué frecuencia los propios sacerdotes se aficionan a intervenir en cuestiones políticas... Pero por Dios, apártenme a los sacerdotes de las luchas políticas... ${ }^{22}$.

No obstante lo indicado, la Jerarquía Católica española seguirá recelando de la decisiva influencia de la Falange en la nueva organización, que considera muy superior a la del Carlismo, ${ }^{23}$ más próxima a los postulados del catolicismo tradicional español, y ello, fundamentalmente por la «influencia tendenciosa de los alemanes, que han infundido o tratan de infundir en Falange Española, según hechos que no dejan lugar a duda, el espíritu absorbente y conquistador del

${ }^{21}$ Documento 6-200. Sección 1. ${ }^{\text {a }}$ Legajo D. Carpeta IV 4. Documento 5. Archivo Gomá.

${ }^{22}$ Sección 1. ${ }^{\circ}$ Legajo D. Carpeta IV. Documento 7. Archivo Gomá.

${ }^{23}$ No obstante la manifestación hecha por Isidro Gomá al Cardenal Pacelli el 12 de mayo de 1937, en la que sostiene la opinión de que tras el proceso de unificación, "Hoy puede afirmarse que está en franca decadencia el viejo espíritu de la Falange y que por la prudente selección de los individuos que forman el Secretariado directivo de la unión de milicias, éstas formarán un gran cuerpo auxiliar del Ejército, sin matiz político alguno y sin más influencia en la cosa pública que la que, de cuerdo con el Jefe del Estado, consienta el Secretariado, en el que predomina el sentido tradicionalista». Documento 5-299. Sección 1. ${ }^{a}$ Legajo: A. Carpeta III. Documento 10. Archivo Gomá. 
hitlerismo ${ }^{24}$. En este contexto son numerosos los roces entre la concepción totalitaria del Estado de la Falange y los intereses de las instituciones católicas.

Sobre la influencia alemana en el Bando Nacional, el Primado de España en el documento reseñado en la nota anterior, manifiesta que la influencia alemana se percibe en las altas esferas de gobierno, destacando la actitud del Embajador alemán Sr. Faupel ${ }^{25}$, que entre otros aspectos defiende la no confesionalidad del Estado, concepto que «empieza a cundir entre los prohombres del gobierno»; así como la influencia de la ideología nacional socialista en aspectos básicos como el Frente del Trabajo, organizado por un alemán, la Comisión Nacional de Prensa, los medios de difusión, poniendo el ejemplo al respecto de que la emisora Radio Castilla es propiedad de Alemania, la educación, donde los falangistas quieren disolver la Asociación de Maestros Católicos, a favor del Sindicato Español de Magisterio, controlado por la Falange, llegándose incluso por parte de delegados del Secretariado de la Unión a solicitar a los Requetés que procuren moderar sus manifestaciones religiosas, acompañando estos requerimientos de graves amenazas personales. Así mismo, relata el Primado se producen frases desconsideradas hacia el Sumo Pontífice y otros dignatarios eclesiásticos. Como conclusión de estos hechos, el Cardenal Gomá, manifiesta «Juzgo pasajera esta situación si hay prudencia en los gobernantes, que habrán de percatarse de que no se puede tocar lo que está tan arraigado en el alma de un país, como es la devoción en España a la Santa Sede. Creo que cuando cese la influencia directa de algunos elementos extranjeros habrán de centrarse otra vez las cosas ${ }^{26}$. "Cantaré un Te deum, me decía un elemento destacado del Cuartel General, el día que salga de España el último alemán"; sin duda habrá desaparecido el principal elemento de perturbación espiritual» ${ }^{27}$.

${ }^{24}$ Informe de Isidro Gomá al Secretario de Estado del Vaticano del 25 de junio de 1937. Sección 1. ${ }^{\circ}$ Legajo A. Carpeta III.. Documento 48. Archivo Gomá.

${ }^{25}$ Wilhelm von Fapel, militar de profesión, en noviembre de 1936 fue nombrado embajador de Alemania ante el General Franco, desempeñando dicho cargo hasta marzo de 1937; nacional socialista fue uno de los más firmes baluartes de la Falange.

${ }^{26}$ El Cardenal Gomá sostendrá siempre que la influencia alemana en España tendría siempre el límite de la religión, pues mientras la de los germanos era predominantemente protestante, en España el catolicismo estaba fuertemente acendrado en la cultura y las costumbres; véase al respecto el informe que remite al Cardena

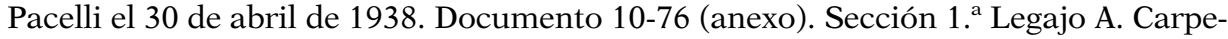
ta IV. Documento 26. Archivo Gomá.

${ }_{27}$ No obstante, lo que podríamos calificar como de cierta obsesión de la jerarquía católica española, especialmente del Cardenal Primado por la Falange, aunque mucho menor, pero en cierto sentido parecido a la referente a la Masonería, le llevará a afirmar, en clave de discreta insinuación «El peligro, que no hago más que insinuar, es que ciertos elementos de la Falange, en contacto clandestino con el jefe del socialismo 
La insistencia del Cardenal Primado contra la influencia alemana en las costumbres españolas llega a solicitar del Ministro del Interior Serrano Suñer ${ }^{28}$ que se acabe con el intercambio de jóvenes españoles que visitan Alemania, y ante el silencio ${ }^{29}$ de éste al propio General Franco $^{30}$ "... porque, antes de tener formado el -sentido moral- (los jóvenes), van a un país pagano, de criterios, costumbres y prácticas (hasta en los últimos detalles inmorales y pagano-racistas... Nadie mejor que Vuecencia aprecia el caudal enorme de energías del pueblo espanol para salvar sus tradiciones tesoro patrio en cultura, en fe, en costumbres...».

En todo caso, la relación entre la Falange y la Iglesia, incluida en esta las correspondientes con el Vaticano, mejorarán muy significativamente con motivo del reconocimiento oficial del régimen franquista por parte de Roma ${ }^{31}$, aspecto en el que destacados miembros del partido único habían sido especialmente críticos y duros con la política vaticana; a este respecto, con tal motivo el secretario político de FET y de las JONS, remitirá al Cardenal Primado el siguiente telegrama, en el que proclama la comunidad de intereses entre su partido y los postulados pontificios en materia social, así como la importancia del catolicismo en los principios inspiradores de la falange «Con motivo reconocimiento oficial del estado de Franco por su

español, Sr. Prieto, y del izquierdista republicano Don Miguel Maura, habían logrado hacer de Falange un partido politico permeable a los elementos socialistas y comunistas que, ante la perspectiva del triunfo del movimiento nacional, se acogían a Falange para luego, de acuerdo con las masas del Frente Popular, desviar el movimiento o hacerlo

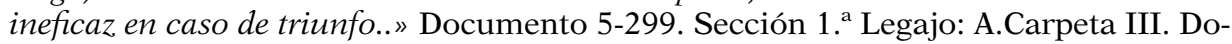
cumento 10.Archivo Gomá.

${ }^{28}$ Documento 11-19. Sección 1. ${ }^{\text {a }}$ Legajo F.Carpeta III.Documento 80. Archivo Gomá.

${ }^{29}$ El trece de julio respondería el Ministro indicando que ciudaban con gran interés la presencia (de los jóvenes) en hechos y doctrinas de ese "gran país amigo».Documento 11-70. Sección 1. ${ }^{\mathrm{a}}$ Legajo F. Carpeta III. Doc.s/c. Archivo Gomá.

30 Documento 11-74.. Sección 1. ${ }^{a}$ Legajo B. Carpeta II. Doc s/c. Archivo Gomá.

31 No obstante, debe destacarse la escasa relevancia oficial que el Vaticano quiso dar al reconocimiento el encargado de Negocios D. Pedro Churruca de Aycinema, como pone de manifiesto la nota de la oficina de información, de la Secetaría General de S.E. el Jefe del Estado «La ceremonia desarrollóse con gran simplicidad...._Ninguna personalidad del Vaticano le esperaba en el patio de San Dámaso. El Marqués de Aycinema dirígese directamente allí donde se encontraba el Cardenal Pacelli. Documento 7-258. Sección 1. ${ }^{\text {a }}$ Legajo F. Carpeta VII. Documento 90. Archivo Gomá. Posteriormente, el 26 de septiembre, el Cardenal Gomá, en escrito al Sr. Sangróniz, matizaría la información anterior, «me complazco en asegurarle que se ha llevado a cabo ( se refiere a la presentación de credenciales del Marqués de Aycinema)conforme a todas las reglas que suelen seguirse para los Encargados de Negocios(categoría distinta de la de los Embajadores y Ministros). Documento 7-515. Sección Varios. Legajo I-VIII. Carpeta VII. Documento sin clasificar. Archivo Gomá. 
santidad Falange Española tradicionalista que por ser expresión del pueblo español que es eminentemente católica y romana y lucha por los principios cristianos de justicia social que inspiraron documentos sociales pontificios ruega a vuestra eminencia comunique al Santo Padre Filial adhesión...» 32 .

A este cambio de actitud se referirá el propio Cardenal de Toledo, en carta dirigida al Secretario de Estado del Vaticano, "En informaciones anteriores...., hacía notar la tendencia laizante de algunos organismos oficiales, especialmente la Falange, cada día más poderosa y absorbente. Señalo hoy dos datos de importancia, que podrían ser reveladores de un cambio de conducta en los altos planos de gobierno de dicho organismo... ${ }^{33}$. En este sentido, cabe destacar la petición de Serrano Suñer, cuñado del General Franco, Secretario político general de Falange Tradicionalista y uno de los más firmes baluarte de la ideología fascista, incluso de carácter germanófilo dentro del partido único nacional, en la que solicita del Cardenal Gomá la organización de asistencia religiosa de las Juventudes del partido.

No obstante, la disparidad de intereses entre la Iglesia española y la Falange persistirán, manifestándose en aspectos como la obligatoriedad de la enseñanza religiosa en la escuela, y el reclutamiento de profesores de la asignatura de religión, que la Iglesia desea su absoluto control, mientras que la Falange deseaba mantener el control de la autoridad civil al respecto ${ }^{34}$; así como la imposición del sindicato único, lo que perjudicaría a los sindicatos católicos y agrupaciones ${ }^{35}$ bajo la tutela de la Iglesia ${ }^{36}$.

32 Documento 7-298. Sección 1. ${ }^{\mathrm{a}}$ Legajo A. Carpeta III. Documento 112. Archivo Gomá.

33 Ibídem.

${ }^{34}$ Esta batalla la ganaría la Iglesia al reconocerse que debían ser los sacerdotes los que impartieran la materia, debiendo ser autorizados para ello por sus respectivos prelados. BOE.8 de octubre de 1938.

${ }_{35}$ A este respecto, es muy clara la exposición de Gomá ante el General Franco de 10 de julio de 1938, referente a la integración de la Confederación Católico-Agraria en la estructura sindical del Estado. Documento 11-54. Sección AFT. Legajo 5/14. Carpeta XIII. Doc.s/c.Archivo Gomá.

${ }^{36}$ Resulta muy esclarecedor sobre el concepto del sindicalismo de la Iglesia, la carta que remite el Cardenal Leopoldo Eijo Garay al Cardenal Gomá, en la que manifiesta su opinión en muchos aspectos sobre la actitud de la Falange y el fascismo en general, «(...) En efecto, la Falange española de las Jons propugnó siempre esa fusión (se refiere al concepto de sindicato único) de todas las corporaciones en las únicas de ella; su formación, en idearios extranjeros la lleva a ello; y lo sigue procurando hasta con ribetes de violencia... el concepto totalitario que del Estado tienen el fascismo y el nazismo inducirá más pronto o más tarde a los falangistas puros a absorber las corporaciones... debe resistirse cuanto se pueda, e influir contra las ideologías nazista, fascis- 
El recelo de la Iglesia se mantendría durante todo el periodo de la guerra civil ante el control que la Falange quería ejercer en todas las instituciones reorganizadas o de nueva creación, «se nota sobre todo su tendencia minimista en cuestión de religión y moral y la facilidad con que pueden introducirse abusos en los organismos en que se traducen aquellas obras si no se extrema la vigilancia. Sin duda se nota la influencia extranjera en la implantación de estos servicios.... ${ }^{37}$.

Respecto a la opinión del Cardenal Gomá referente a lo que considera intromisión de la Falange en los asuntos eclesiásticos y el papel predominante de la misma en el Nuevo Estado, así como sobre uno de los mitos más importantes de esta organización política, el denominado Ausente, José Antonio Primo de Rivera, fundador y máximo ideólogo del partido único, el Primado en fecha de 16 de noviembre de 1938, lleva a cabo de unas consideraciones, que en la opinión que sostenemos son únicas y muy diferentes de la actitud oficial que la Iglesia española mantendrá durante los casi cuarenta años que duraría el régimen surgido del 18 de julio de 1936.

El motivo de las mismas es la visita que D. Julián Pemartín, vicesecretario de FET y de las JONS, acompañado del Sr. Villalonga hacen al Cardenal Gomá con el fin de que con motivo del segundo aniversario de la muerte del fundador de la Falange se llevasen a cabo en todas las iglesias españolas funerales por el alma del mismo, así como que en la parte exterior de las mismas se pusiera una lápida con los caídos de la localidad, encabezado en todos los lugares por en nombre de José Antonio Primo de Rivera ${ }^{38}$.

Sobe estas peticiones el Primado respondió que escapaban a sus funciones y debía consultarlas con el Nuncio, una vez llevadas a cabo y tras la decisión de Monseñor Cicognani de que la misma la tomara el propio Gomá, éste contestó a Pemartín que respecto a los funerales por el alma de José Antonio, el Nuncio le había comunicado que no estaba en sus atribuciones concederlo, pero que solicitaría el permiso correspondiente a la Santa Sede, y en relación a las lápidas conmemorativas de la muerte del fundador de la Falange, era mejor diferir

\footnotetext{
ta, incompatibles con la ética cristiana...». documento 8-17. Sección D. Legajo D. Carpeta V. Documento 6.

37 Carta del Cardenal Gomá a monseñor Antoniutti denunciando la influencia extranjera en la orientación moral de las nuevas obras sociales del Estado, de 4 de abril de 1938. Documento 10-9. Sección 1. ${ }^{a}$ Legajo B. Carpeta I. Documento 58. Archivo Gomá.

38 Documento 12-140. Sección 1. ${ }^{a}$ Legajo B. Carpeta II. Documento 49. Anexo 4. Archivo Gomá.
} 
el homenaje para cuando se pueda hacer conmemoración de «tantos como han dado su vida por la patria» ${ }^{39}$.

Sin embargo, la opinión al respecto del Cardenal Gomá es mucho más explícita y sincera en el escrito del 16 de noviembre que remite al Nuncio Cayetano Ciccognani, en la que manifiesta sin ambages su opinión sobre el fundador de la Falange y la actitud prepotente de la Falange imponiendo sus criterios sobre los tradicionalistas y otros órganos del Estado. A tal efecto, reproducimos a continuación algunos párrafos de la citada carta:

a) La cuestión tiene todo el aspecto de un artificio político, forzosamente pasajero, al que la Iglesia no debiese incorporarse en forma tan solemne, bastándole cubrir las atenciones oficiales y los oficios de caridad, con la fórmula que yo propuse al delegado del Partido, y que me había sido sugerida por Vuecencia, de celebrar una misa en sufragio del alma del difunto, y luego un responso solemne a la misma intención.

b) El difunto Sr. Primo de Rivera, que en paz descanse, contrajo sin duda estimables méritos en el movimiento de reacción contra el gobierno de la República y sus grandes yerros; pero dista mucho de ser el hombre que encarne el movimiento actual, aunque sí puede decirse que es el hombre representativo de Falange, por él fundada ... hombre, representativo sí, pero de mucho menos valer e influencia social que otros hombres que por ahora permanecen poco menos que en el olvido..Hoy tiene Primo de Rivera el valor de un mito que se está creando artificialmente, y que los dirigentes de Falange han juzgado necesario, tal vez por la carencia de una ideología politica fuerte o de un hombre que se haya impuesto por su valer. Asi se ha levantado una bandera para agrupar multitudes, de las que andaba sobrante el sector de FET interesado en este homenaje póstumo. Creo que la Iglesia ha de andar con mucho tiento en este punto, por cuanto alrededor de este nombre se acumula una literatura tendenciosa, que remeda orientaciones extranjeras reprobables en la marcha política de un Estado cristiano.

A continuación el Primado remite varias referencias a la figura de José Antonio publicadas en la prensa nacional en la que tratan al caído como elemento elegido de la divinidad y llamado a la santidad..... Creo que bastan estas indicaciones para recelar en la colaboración a esta obra de divinización de un hombre. Añado que se anuncia la publicación de una oración dirigida al homenajeado, como se hace con los

39 Documento 12-165. Sección AFT. Legajo: 5-14. Carpeta VI. Documento 6. y Documento 12-168. Sección 1. ${ }^{a}$ Legajo B. Carpeta II. Documento 53. Anexo 3. Archivo Gomá. 
santos, para impetrar el auxilio divino. No la conozco todavía. Continúa con una crítica a la Falange «Nadie puede negar la profunda desazón sentida por gran parte del pueblo español ante el rumbo que toman las cosas; rumbo que han impreso a la nación los autores del homenaje, sirviéndose principalmente del nombre y recuerdo del Sr. Primo de Rivera»..habrá de molestar a quienes ni comulgan con el movimiento particularista, ni han visto hacerse justicia a figuras más representativas del tablero nacional.

Nunca, ni a los Reyes de España, se concedieron a nadie tales honores...El precedente podrá ser funesto, viéndonos obligados con demasiada frecuencia a la celebración de actos análogos, que tienen todo el carácter de una parada, y la dispensa sin razón suficiente de una ley litúrgica. Acaba su carta el Primado quejándose del procedimiento imperativo seguido por los falangistas, que en su opinión no han respetado el procedimiento jerárquico de la Iglesia y el protocolo al respecto; por último vuelve a exponer su queja por la forma inconsiderada con que la Falange impone sus personas y criterios en detrimento de los elementos tradicionalistas ${ }^{40}$.

\section{SOBRE EL CLERO FALANGISTA}

Especial motivo de preocupación para la jerarquía católica española fue la influencia de la ideología falangista en ciertos sectores del clero español, aspecto que siempre fue mirando con gran recelo por la misma ${ }^{41}$, siendo el caso más sonado el nombramiento del sacerdote Fermín Izurdiaga como Consejero Nacional, que intentó evitar la jerarquía eclesiástica ${ }^{42}$, por cuanto significaba una clara utilización de

${ }^{40}$ Documento 12-177. Sección 1. ${ }^{\mathrm{a}}$ Legajo B. Carpeta II. Documento 55. Archivo Gomá.

${ }^{41}$ Ello no obsta, para la existencia de algunos sacerdotes marcadamente falangistas, aspecto que siempre fue condenado por la jerarquía católica española «Eso de que ese sacerdote vestido de falangista sucio y desaseado, vaya discutiendo de pueblo en pueblo como -capellán camarada-, me parece que no tiene asidero... En el próximo número del Boletín reproduzco el artículo del Reglamento provisional que habla del traje de los castrenses, digo que es aplicable a los Presbiteros-reclutas y reconocido por los Encargados de iglesias que no admiten a quien no lleve hábitos talares...». Carta de D. José Miralles, Obispo de Palma de Mallorca al Cardenal Gomá referente a la actuación política del sacerdote Sagresse. Documentos 7-246. Sección 1. ${ }^{a}$ Legajo C. Carpeta III. Documentos 116 y 117 Este mismo Obispo manifestó su queja al Primado por la militarización de sacerdotes de su diócesis, que de esta forma quedaba desasistida en su opinión. Vid. Documento 12-72. Sección 1. ${ }^{\mathrm{a}}$ Legajo C. Carpeta V. Documento 176 .

${ }^{42}$ «Se ha producido un hecho lamentable, que no he podido evitar. Después del episodio ocurrido en la cuestión de Don Fermín Izurdiaga, con las comunicaciones que el 
la Iglesia para los fines del régimen ${ }^{43}{ }^{44}$.De hecho uno de los acuerdos de la Conferencia de Metropolitanos celebrada en Dueñas (Palencia) los días 11 a 13 de noviembre fue prohibir al sacerdocio llevar insignias o prendas de las agrupaciones de carácter político, así como que prestaran servicio de ninguna clase en organizaciones políticas, si no fuera con previa aprobación del Ordinario y según las normas que éste dictare ${ }^{45}$. El propio Encargado de Negocios de la Santa Sede, Monseñor Antoniutti, informaría al Vaticano de la actitud de Izurdiaga, que según expresión del citado diplomático al Obispo de Pamplona sintió un profundo dolor y expresó su deseo de que se empleara el máximo rigor por parte de la jerarquía católica española para este tipo de actuaciones de los religiosos ${ }^{46} 47$.

Sr. Obispo de Pamplona y yo dirigimos al Generalísimo, y cuando fundadamente esperábamos que se le relevaría del cargo de Presidente de la Delegación Nacional de Prensa, en el que estos últimos días había obrado de manera indiscretísima que ya le diré, me he enterado con pena que dicho Sr. sacerdote ha sido nombrado Consejero Nacional, entre los cincuenta prohombres elegidos para este importantísimo cargo..Son de lamentar fondo y forma en este desgraciado negocio...., ni a mi se me ha dicho una sola palabra para un nombramiento esencialmente de carácter político. Si en el Consejo debía figurar un sacerdote, no es este el llamado a ello, ni debía tenerse esta lamentable desatención con la Iglesia». Carta de Gomá a Mon. Antonioni., de 27 de octubre de1937. Documento 8-176.Sección 1. ${ }^{\text {a }}$ legajo B. Carpeta I. Documento 28.Archivo Gomá.

${ }_{43}$ «no creo que tenga remedio: es un testaferro que les conviene a los del Cuartel, incluso en lo más arriba, para menesteres menos finos»Carta de Gomá a Luís de Despujols. Documento 8-189. Sección números romanos. Legajo L-LII. Carpeta XLIX. Documento 63b. Archivo Gomá. De hecho la no satisfacción de la Jerarquía católica española se pone de manifiesto en el cruce de telegramas entre el Obispo D. Gregorio Modrego y el Primado, con motivo de la invitación hecha al primero para asistir a la jura de los nuevos consejeros nacionales, cuya conveniencia plantea Modrego al Primado, a lo que este responde "Agradezca invitación manifestando motivos ausencia". (Gomá si acudió).Documentos 8-363 y 8-367. Sección: Números Romanos. Legajo L-LII. Carpeta LII. Documentos s/c y 169. Archivo Gomá.

${ }^{44}$ Sobre la importancia otorgada por la jerarquía católica a este sacerdote, es muy representativa la carta que el Cardenal Gomá remite al Nuncio Cicognani el 27 de octubre de 1938, en la que refiriéndose a una propuesta de concesión de honores para los miembros del Consejo Nacional... militares el de Capitán General, civiles a ministros..y para los eclesiásticos la asimilación sería la que corresponda a los arzobispos..»Prescindiendo del hecho de que en la actualidad no hay más que un consejero sacerdote, y que su asimilación a arzobispo sería recibida con una carcajada general.... ".Documento 12-84. Sección 1. ${ }^{\mathrm{a}}$ Legajo B. Carpeta II. Documento 40. Archivo Gomá.

45 Actas de la Conferencia de Metropolitanos; en Anexo a Documento 8-371. Sección 1. ${ }^{\mathrm{a}}$ Legajo D.Carpeta IV.Archivo Gomá.

${ }^{46}$ Carta de Moseñor Antoniutti al Obispo de Pamplona. Anexo a Documento 9-73. Sección 1. ${ }^{\text {a }}$ Legajo B. Carpeta I.. Documento 40. Anexo. Archivo Gomá.

${ }^{47}$ Como consecuencia de estas medidas, Izurdiaga, no pudo asistir al Consejo Nacional del Movimiento celebrado en las Huelgas de Burgos del 5 al 8 de junio de 1938, ya que no fue autorizado por el Obispo de Pamplona. No obstante siguió siendo consejero nacional del movimiento hasta 1967 y fue canónigo magistral de la catedral de Pamplona y caballero de la Gran Orden Imperial del Yugo y Las Flechas. 
No obstante, los intentos de la Falange por incorporar el bajo clero a sus organizaciones no cejó en todo el periodo, valga el ejemplo de la carta que Rigoberto Doménech, Arzobispo de Zaragoza, remite al Cardenal Gomá el 3 de abril de 1938 «... Días pasados se me presentó uno de los capellanes que están en Falange diciéndome que por orden del Delegado provincial y con la anuencia de la-jerarquía-se dirigieran a a los Curas Párrocos y Ecónomos de los pueblos instándolos a tomar parte en las obras de Falange.. Me tenían preparada una Circular para enviarla a todos los Curas del Arzobispado... ${ }^{48}$, a lo que el citado Arzobispo se negó argumentando al Primado. «...Si necesitan algo del Párroco o Sacerdote, preséntense y pidan sus servicios, pero meter brutalmente en Falange a los Curas de esta manera, era además de inoportuno, contrario a las normas canónicas. Porque Falange tiene el carácter de partido político y la Santa Sede, con gran prudencia y acierto, ha manifestado su voluntad de que el Clero permanezca alejado de la política». La respuesta del Cardenal Gomá confirmó tal decisión «Mi parecer es que se debe negar en redondo a dar su autorización para que sus sacerdotes se encuadren en los servicios de Falange como tal...se trata de un partido y no debe haber sacerdotes de partido...» ${ }^{49}$.

Posteriormente en la entrevista mantenida con el General Franco, el Primado insistirá en la necesidad del alejamiento de la política de los eclesiásticos, indicando que «las autoridades civiles no debiesen jamás requerir los servicios de un sacerdote o religioso sin previo acuerdo con sus superiores, evitando asi posibles infracciones de las disposiciones canónicas y tal vez el descrédito de sacerdotes que se han desplazado de sus ministerios... le alego el caso de Yzurdiaga, a lo que calla; y el caso de Pérez de Urbel, a lo que me dice que tiene permiso de su Abad...» ${ }^{50}$.

Mención especial merece también el caso del fraile Justo Pérez de Urbel, personaje que tuvo un papel destacado, en virtud de su actuación en el asunto de la clausura de la Revista Pelayos, la jerarquía católica fue mucho menos directa, posiblemente como consecuencia de la relación de éste con los altos jerarcas del Régimen, especialmente con Pilar Primo de Rivera, Jefa de la Sección Femenina, organización en la que tuvo un importante papel como consejero, así en escrito que le dirige el secretario del Primado en nombre de éste, se le manifiesta «Su Eminencia que ha apreciado siempre la gran labor de V. $R$ en sus publicaciones y trabajos y reconocido el bien que mediante ellos puede obtenerse, lamentaría sinceramente que a causa de las ocupaciones actuales tuviera $V$. $R$. que reducir sus actividades literarias $y$

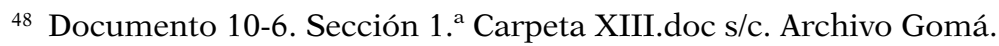
Gomá.

${ }^{49}$ Documento 10-19. Sección AFT. Legajo 5/14. Carpeta XIII. Docs/c. Archivo

${ }^{50}$ Documento 12-274. Sección 1. ${ }^{\mathrm{a}}$ Legajo.s/c. Carpeta s/c. Archivo Gomá. 
hagiográficas que le han ganado el respeto y la consideración de todos por su mérito intrínseco y por estar alejadas de toda política, dando así ejemplo a religiosos y sacerdotes quienes, para no comprometer su misión, han de esmerarse en permanecer fuera y por encima de las diferencias politicas ${ }^{51}$, aunque no deja de advertirle sobre su proceder en el asunto de la desaparición de la prensa católica revista (Pelayos) ${ }^{52}$, "Asimismo me dice Su Eminencia que le manifieste que constituiría para él un grave cargo de conciencia si por tolerancia o debilidad hubiera facilitado la desaparición de un periódico cualquiera que hubiese sido portavoz de las doctrinas de la Iglesia» ${ }^{53}$.

Pérez de Urbel, a diferencia de otros sacerdotes miembros de organizaciones falangistas opta por una vía pretendidamente dialogante y diplomática respecto a la jerarquía eclesiástica, «mil gracias por ante todo al Sr. Cardenal y a V. por los inmerecidos elogios a mis actividades literarias», justificando su actividad y participación en la extinción de la Revista Pelayos como consecuencia de la obediencia debida, «me creo en el deber de hacer una fina aclaración, ya que, a juzgar por algunos términos en que $V$. se expresa, parece $V$. interpretar torcidamente mi actitud... tengo la satisfacción de poder decirle que en primer lugar si he intervenido en la cuestión de-Pelayos-, ha sido cumpliendo la obediencia... el Sr. Ministro me hizo una insinuación; yo le contesté que estaba a las órdenes de mi P. Abad; entonces el Ministro vino a ver al P. Abad y yo no tuve más remedio que aceptar lo que había sido convenido entre ello ${ }^{54}$. No contento con eso consulté a mi Prelado el Sr. Arzobispo de Burgos, el cual dio su aprobación y bendición... ${ }^{55}$. Si le voy a ser franco debo confesar

${ }^{51}$ Documento 12-44. Sección: AFT. Legajo 1-4. Carpeta I. Doc.s/c. Archivo Gomá.

${ }_{52}$ La revista Pelayos pertenecía a la Comunión Tradicionalista. Como consecuencia de este proceso de aplicación del concepto totalitario de la Falange cabe destacar por ser muy representativo del mismo el cierre de la revista infantil «Pelayos y su inclusión en la prensa del movimiento, realmente su absorción por la revista falangista «Flechas», aunque la entidad periodística resultante fuera "Flechas y Pelayos»; La revista Flechas y Pelayos se publicó desde el 11-XII de 1938 a abril de 1949, siendo su director Fray Justo Pérez de Urbel.

${ }^{53}$ Ibídem.

54 El Cardenal Gomá negará tal extremo; vid al respecto su entrevista con el General Franco del 2 de diciembre de 1938. Documento 12-274. Sección 1. a Legajo.s/c. Carpeta s/c. Archivo Gomá. En el mismo sentido se referirá Gregorio Modrego, Obispo Auxiliar de Toledo, en carta remitida al Primado del 12 de diciembre de 1938, en la que referente al nombramiento de Pérez de Urbel como Asesor Nacional de la Sección Femenina de FET de las JONS, afirma «Desearía saber con qué autorizaciones cuenta ese $P$. y hasta qué punto habría que respetar las normas que diera para la actuación de los Asesores locales, si llegara a darla, o instrucciones cualesquiera. Yo no estoy dispuesto a admitir intromisiones que sepan a jurisdicción exenta, sino de quien únicamente pueden darla».Documento 12-295. Legajo L-LII. Carpeta L-III. Documento 133. Archivo Gomá.

55 En carta del 28 de noviembre de 1938, dirigida a D. Mariano Vilaseca,el Prior Luciano Serrano, Abad de Silos, niega que haya autorizado tal medida, «...sabe $V$. también que me parecen justificadas las quejas de V sobre el proceder de quien me habla

() UNED. Revista de Derecho UNED, núm. 19, 2016 
que esto me contrariaba porque me sacaba de mis trabajos ordinarios y me metía en un campo para el cual reconozco que no estoy preparado, aunque por otra parte lo aceptaba de buen grado por ayudar a un Gobierno que lo ha salvado todo en la Iglesia de España y en el cual veía yo una buena voluntad incondicional»; ${ }^{56}$ posteriormente, en el mismo escrito, en clara referencia a la absorción de la Revista Pelayos, indica, «Creo necesario advertir que cuando a mi me metieron en este asunto se había tomado ya una resolución radical con respecto a él. En mi primera conversación con el Sr. Ministro conseguí que no se precipitasen las cosas, y que por el momento nos contentásemos con hacer una fusión de ideas...».

En correos posteriores Pérez de Urbel, ante la jerarquía católica, seguirá auto exculpándose por su actitud de entrega ante el Ministerio, así en carta a Gomá de 12 de noviembre, manifestará «No me ha sido posible evitar lo que ya se podía prever cuando me vi obligado a intervenir en este asunto de las revistas infantiles...Por mi parte creo deber mío después de consultar el parecer de mis superiores jerárquicos, responder a la confianza, que no sé por qué depositan en mí. Es un deber enojoso y delicado, pero me veo en la necesidad de asumir, dadas las circunstancias anormales por que atravesamos... ${ }^{57}$.

\section{CONCLUSIONES}

La jerarquía católica española apoyó desde el principio la rebelión militar dirigida por el general Franco, a la que muy pronto calificó de Cruzada, observándose una postura diferenciada con la mantenida por el Vaticano al respecto, que mantenía una clara oposición al nacional socialismo alemán, cuya más clara manifestación es la Encíclica de Pío XI Mit Brennender Sorge, que significa una clara condena de dicha ideología. Respecto a la situación española en el estamento eclesiástico existe un claro recelo ante la influencia del concepto totalitario de la falange e influencia hitleriana en el Gobierno Nacional; a este respecto la jerarquía católica española mantendrá su oposición a que elementos del clero tengan actividad política dentro del partido único, de tal forma, que para aceptar un cargo público los miembros del mismo deben contar con la aprobación de su autoridad eclesiástica superior. Así mismo, se pone de manifiesto el rechazo del estamento eclesiástico al intento de control del nuevo estado sobre la prensa católica.

(Pérez de Urbel), pero creo que por ahora nada se puede hacer sobre ello, máxime habiéndose hecho sin conocimiento mío y en un asunto en que ninguna intervención se me ha dado...»Documento 12-366. Sección AFT. Legajo: 1-4. Carpeta 1. Doc. s/c. Archivo Gomá.

${ }^{56}$ Carta a Luis de Despujols, secretario del Primado. Documento 12-56. Sección AFT. Legajo. 1-4. Carpeta 1. Doc. s/c. Archivo Gomá.

57 Documento 12-160. Sección AFT. Legajo 1-4. Carpeta I. s/c. 